\title{
Parameter Sensitivity Analysis of Shrinkage Effects on Concrete Continuous Girder Bridge
}

\author{
Xiaotian $\mathrm{HaO}^{1, \mathrm{a}^{*}}$ \\ ${ }^{1}$ Chongqing Technology and Business Institute, No.15 Siyuan Road, College Park, Hechuan, \\ Chongqing, China \\ ahaoxiaotian369@163.com
}

\begin{abstract}
Keywords: Continuous Box-girder Bridge; Shrinkage Effects; Parameter Sensitivity
Abstract. Due to the effect of concrete shrinkage, bridge alignment and internal force can be influenced in the process of construction. Taking a three-span prestressed concrete continuous bridge as an example, a finite element analytical model was built by using Midas Civil FEM software. The effect of parameters such as environmental relative humidity, loading age and bridge operation period have on internal force distribution and displacement response of Concrete girder caused by shrinkage effect were obtained in this paper. Based on the analysis of three controllable factors mentioned above, a conclusion was drawn that shrinkage effects were going up along with the increase of environmental relative humidity and bridge operation period, and going down when loading age was put off. Therefore, depending on the sensitivities of vertical displacement and internal force response of concrete girders, advice to reduce shrinkage effects in the construction process was listed in this paper.
\end{abstract}

\section{Introduction}

Prestressed concrete continuous girder bridge was a kind of classical structure system, and also had reasonable mechanical performance, small deformation, beautiful shape and long spanning capability relatively to other systems, so this type has been widely used in the past few decades in China [1][2].

Along with a large-scale construction, effects on structural internal force and displacement caused by concrete shrinkage have been paid more attention. Current research works showed that geometrical characteristics of girder, materials, casting, maintenance and Environmental conditions that were important factors which affected concrete shrinkage, and those would end up causing a certain effect to structural internal forces and displacement[3][4][5].

While predicting the development of concrete shrinkage regularity and its influence on structure performance methods were constantly developing, influence degree on the structural performance caused by shrinkage still need to be further in-depth study.

\section{Engineering Background}

Taking a three-span prestressed concrete continuous bridge as a engineering background, From the perspective of varying parameters which would have an effect on structural behavior, Environmental Relative Humidity (hereafter referred to as ERH),Loading Age ( LA )and Bridge Operation time ( BOT ) have been chosen to analysis parameter sensitivity on concrete continuous girder bridge shrinkage effects. The span of this bridge was 55+100+55m (shown in Fig.1), girder was single box single chamber section, widths at the top and down of box girder were respectively $12.5 \mathrm{~m}$ and $6.5 \mathrm{~m}$, The changes of the beam's height was using a1.8 parabolic curve from mid-span to pier top section .the height of mid-span and pier top section were respectively $2.85 \mathrm{~m}$ and $6.25 \mathrm{~m}$ (shown in Fig.2). According to the principles of discrete structure, and then using Midas Civil software finite element analytical model has been built (shown in Fig.3). 


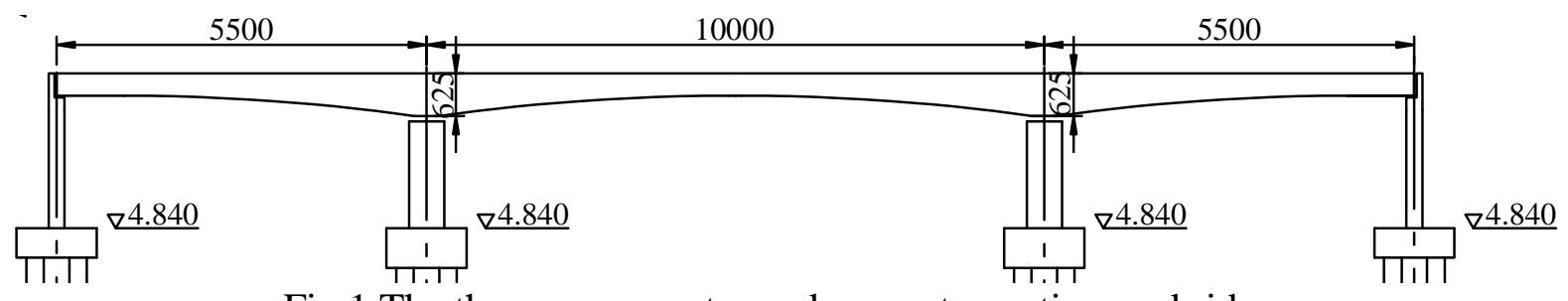

Fig.1 The three-span prestressed concrete continuous bridge

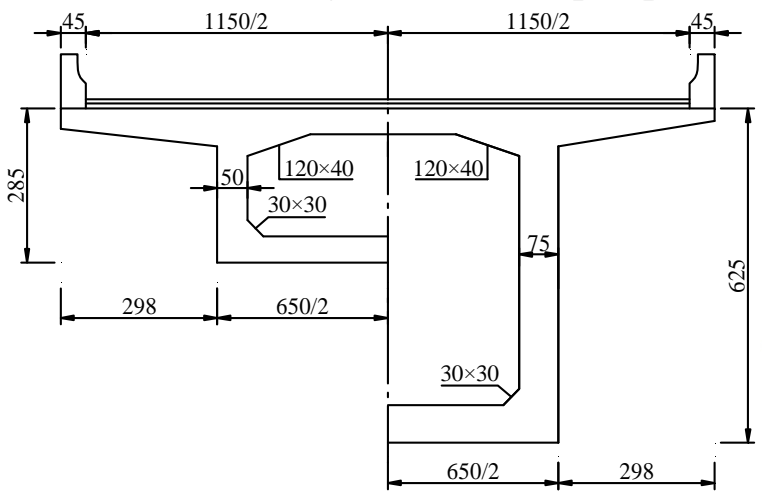

Fig. 2 Cross section of box girder Fig.3 Finite element analytical model

In the process of construction stage, because of accumulate concrete shrinkage effects on static performance the whole bridge had been obviously influenced. Therefore, from the perspective of changing values of parameters that would affect concrete shrinkage, this paper have studied on results of structural internal forces and displacement caused by changing values of those parameters, such as ERH,LA and BOT, static performance rules on the background bridge effected by shrinkage have also been obtained.

Combined with the environmental conditions and construction scheme of the bridge, values of ERH, LA and BOT have been shown in Table.1. Using finite element analysis, results of vertical displacements and bending moment under the corresponding parameter condition in control sections was obtained and shown in Table 2 and Table 3. Via such means, static behavior of this bridge affected by concrete shrinkage would be studied in this paper.

Table.1 Different values of parameters

\begin{tabular}{c|c|c|c}
\hline Parameter & \multicolumn{3}{|c}{ Values } \\
\hline ERH /\% & 40 & 60 & 80 \\
\hline LA /Days & 4 & 7 & 14 \\
\hline BOT /Days & 300 & 1000 & 3000 \\
\hline
\end{tabular}

Table 2 Vertical displacements in control section caused by different value of ERH, LA and BOT

\begin{tabular}{c|c|c|c|c|c|c|c|c|c}
\hline \multirow{2}{*}{ Location } & \multicolumn{3}{|c|}{ ERH } & \multicolumn{3}{c|}{ LA } & \multicolumn{4}{c}{ BOT } \\
\cline { 2 - 13 } & $40 \%$ & $60 \%$ & $80 \%$ & 4 D & 7 D & 14 D & 300D & $1000 \mathrm{D}$ & $3000 \mathrm{D}$ \\
\hline Side-pier Top & 0.000 & 0.000 & 0.000 & 0.001 & 0.000 & 0.000 & 0.41 & 2.47 & 6.82 \\
\hline Middle of Side-Span & -0.094 & -0.078 & -0.049 & -0.049 & -0.050 & -0.052 & 8.91 & 5.29 & 7.03 \\
\hline Mid-pier Top & 0.014 & 0.012 & 0.008 & 0.008 & 0.008 & 0.009 & 5.91 & 1.34 & 5.41 \\
\hline 1/4 Span of Mid-span & -0.310 & -0.259 & -0.161 & -0.161 & -0.165 & -0.166 & 6.88 & 3.76 & 1.70 \\
\hline Middle of Mid-span & -0.499 & -0.417 & -0.260 & -0.261 & -0.267 & -0.266 & 5.44 & 7.34 & 6.64 \\
\hline Table 3 Bending moments in control section caused by different value of ERH, LA and BOT \\
\hline \multicolumn{8}{|c|}{ ERH } \\
\hline
\end{tabular}


Environmental Relative Humidity ( ERH ). When ERH was 40\%, 60\% and $80 \%$ respectively, internal force and displacement have been analyzed, and then the influencing degree caused by shrinkage in static behavior was got. The changing rules of vertical displacement and bending moment along with changes of ERH were shown in Fig.4, Table.2 and Table.3..
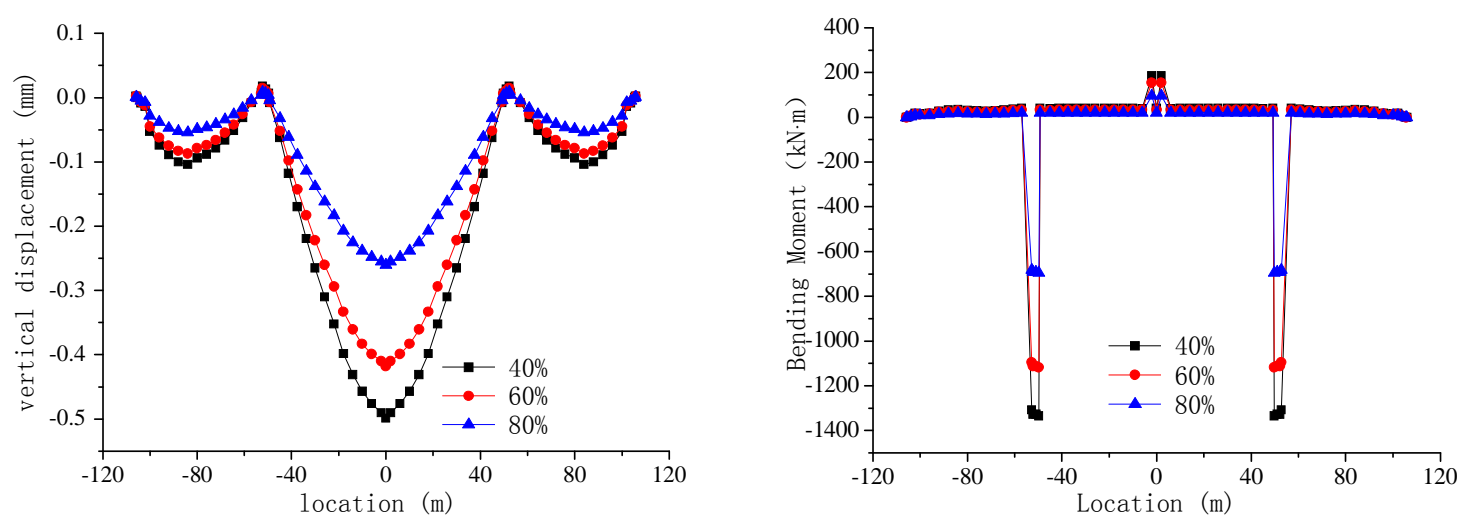

Fig.4 Vertical displacements and bending moments caused by different values of ERH

Vertical displacement of continuous girder caused by concrete shrinkage was about symmetry in the mid-span cross section position, and results decreased along with the ERH value reduction. Displacement in the middle of mid-span was the biggest caused by concrete shrinkage through changing ERH values. From $40 \%$ increasing to $80 \%$, vertical displacements have decreased $43 \%$. In the meantime, bending moment caused by concrete shrinkage in mid pier top section was the greatest, and that number has reduced almost $48 \%$.

Therefore, when designing, checking and calculating in construction monitoring prestressed concrete bridge, the value of ERH must be based on the existing bridge design specification, combined with bridge site environmental conditions and then choose the appropriate value in order to avoid big error calculated result.

Loading Age ( LA ). When loading age of prestressed concrete continuous box-girder bridge respectively was 4 days, 7 days, 14 days, changing rules of vertical displacement and bending moment were shown in Fig.5, Table.2 and Table.3.
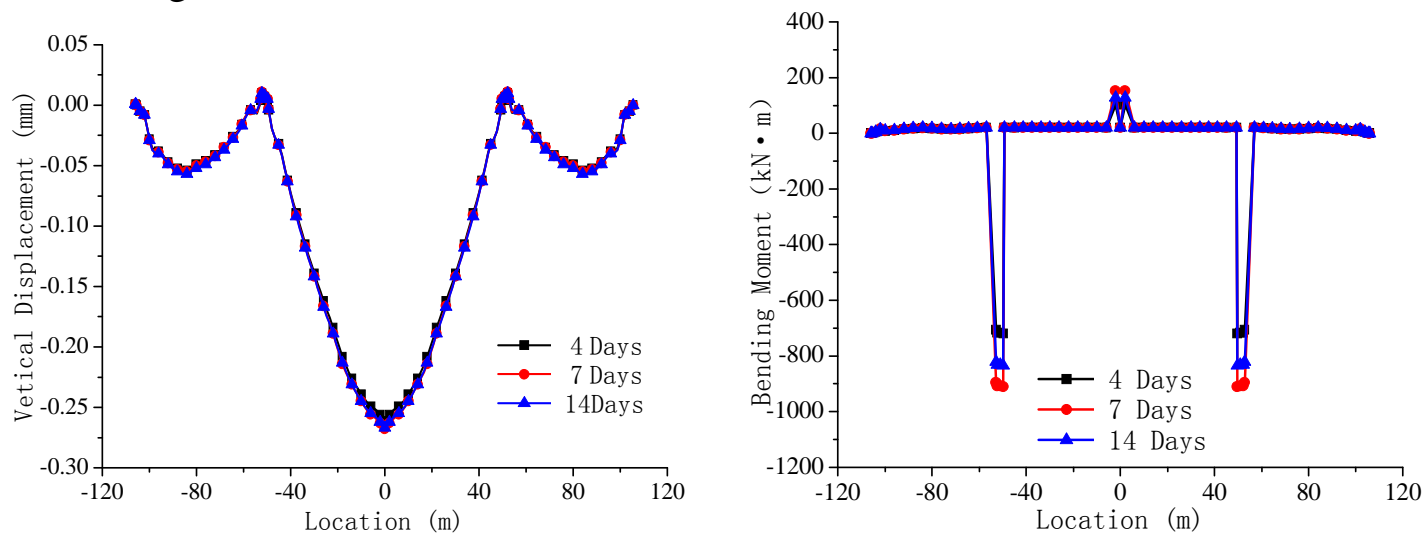

Fig.5 Vertical displacements and bending moments caused by different values of LA

When loading age was increasing from 4 to 14 days, the maximum displacement have reached $0.267 \mathrm{~mm}$ that occurred in middle of mid-span, which has already increased $2.3 \%$, so the longer LA the larger deflection. At the meantime, bending moment in mid-pier top section was affected greater than other sections. When LA increased from 4 to 7 days, value of internal force in continuous girder bridge increased $21.06 \%$, which affected by the concrete shrinkage through varying LA value. Therefore, necessary and reasonable measures would be applied to alleviate negative moment in the construction.

Bridge Operation Time (BOT ). When bridge operation time respectively was 300 days, 1000days, 3000 days, changing rules of vertical displacement and bending moment were shown in Fig.6, Table.2 and Table.3. 

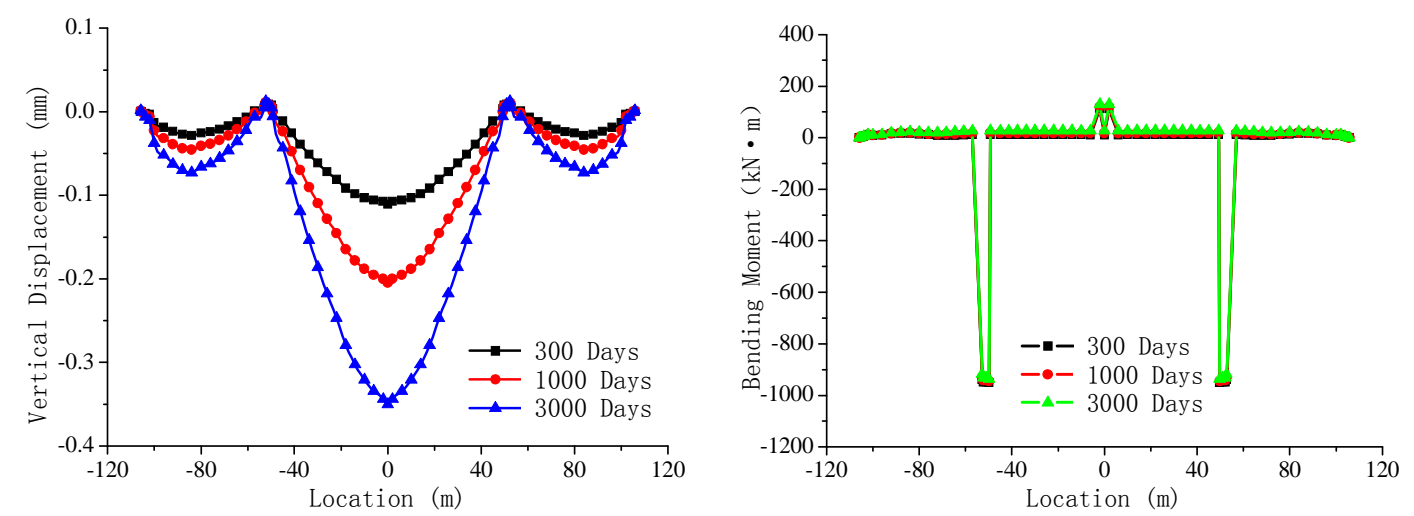

Fig.6 Vertical displacements and bending moments caused by different values of BOT

On the basis of all above results, the longer BOT the larger vertical displacement, and influence that occurred in mid-span was greatest than other sections. Vertical deflection increased about 2.15 times in mid-span, but bending moment of girder caused by varying value from 300 to 3000 days of BOT had a little change.

\section{Conclusions}

Parameters that had influence on concrete shrinkage in continuous girder bridge has been introduced., and also taken an actual bridge as an example, established the whole bridge finite element model to research static behavior of continuous girder bridge, which was affected by concrete shrinkage because of different values of ERH, LA and BOT. Results showed that the bigger ERH the smaller vertical displacement generated, the longer LA the bigger displacement on the contrary. Even though values of BOT had a proportional relation with deflection, but had a little influence on internal force of concrete continuous bridge.

On the basis of all above results, when designing, calculating structure and monitoring during construction of bridge, according to the existing bridge design specifications and actual situation at the bridge site, reasonable values ERH, LA and BOT have been decided carefully, so to avoid big error calculation results which would hide security problems just due to wrong values of parameters.

\section{References}

[1]Jianbin LI, Xianfeng Shi. Shrinkage and creep analysis of continuous prestressed concrete bridge , J.Journal of Shijiazhuang Railway Institute, 2003, 16(2): 16-18

[2] Gengfeng Ren, Jingyu Hu, Ruya Wang, Chunsheng Wang. Research of rational loading age of long multi-span continuous concrete girder bridge, J. Concrete, 2011, 262(8): 73-78

[3]Garden N J , Zhao J W. Creep and Shrinkage Revisited[J].ACI Materials Journal ,1993, 90(3): 36-46.

[4]Lam J P. Evaluation of Concrete Shrinkage and Creep Prediction Models[R]. American: The San Jose State University, 2002,1-200

[5]Hongliang Wang. Impacts of Shrinkage and creep on continuous prestressed concrete bridge, J. Gansu Science and Technology, 2011,27(4):126-12 